\title{
Colombia en posconflicto: ¿turismo para la paz o paz para el turismo?
}

\section{Colombia in Post-Conflict: Tourism for Peace or Peace for Tourism?}

\author{
Miriam Menchero Sánchez ${ }^{1}$ \\ Universidad EAN (Colombia)
}

Recibido: 05-11-17

Aprobado: 25-01-18

\section{Resumen}

El conflicto armado en Colombia ha tenido un impacto directo en su actividad turística, especialmente desde los años 1990 hasta la actualidad, incluyendo el intervalo de 1996 a 2005, considerado como el de mayor auge de inestabilidad en el país, y que influyó en la seguridad, accesibilidad e imagen nacional e internacional de la gran mayoría de los destinos colombianos. Aunque diferentes medidas públicas y privadas lograron mejorar los indicadores turísticos desde la segunda década del siglo XXI, el Acuerdo de Paz con la guerrilla de las FARC, suscrito el año 2016, plantea un nuevo escenario, de posconflicto, en el cual el turismo puede convertirse en uno de los sectores productivos más beneficiados a corto plazo. Lo anterior, repercutiendo tanto en los destinos y productos turísticos tradicionales y emergentes, como contribuyendo a la paz como instrumento de desarrollo sostenible, dada su incidencia en los territorios y comunidades más afectados por la violencia armada.

Palabras-clave: turismo, destinos, seguridad, paz, conflicto armado colombiano y posconflicto.

\begin{abstract}
The armed conflict in Colombia had a direct impact on its tourism activity, fron the 1990s to the present, and which influenced security, accessibility and national e internacional image of Colombia destinations. Although different public and private measures managed to improve the tourism indicators durante

\footnotetext{
${ }^{1}$ (mmenchero.d@universidadean.edu.co). Máster en Gestión del Patrimonio Cultural de la Universidad de Zaragoza e investigadora predoctoral en Turismo de la Universidad Rey Juan Carlos. Profesora Asociada de la Facultad de Administración, Finanzas y Ciencias Económicas de la Universidad EAN, Colombia.
} 
the decade of 2010, the Peace Agreement, signed with FARC guerrilla in 2016, poses a new scenario, in which tourism can become one of the most benefited economic sectors, but also tourism can contribute to peace as an instrument of sustainable development for the communities most affecte by violence.

Key-words: Tourism, Destinations, Security, Peace, Colombian Armed Conflict and Post-conflict.

\section{Introducción}

El turismo es un fenómeno relativamente joven en la subregión turística de América del Sur, aunque su importancia se ha ido constituyendo, poco a poco, como una prioridad de las agencias nacionales de los países que integran este espacio turístico (OMT, 2013: 8). De hecho, aunque parte del turismo en Latinoamérica se ha basado en la creación de productos turísticos de sol y playa -desde principios del siglo XX en el Cono Sur y Brasil, y especialmente, desde 1950, en el Caribe y México-, la coexistencia con otras tipologías turísticas más recientes, vinculadas con el patrimonio cultural y ecológico de la región, así como nuevas propuestas encaminadas hacia la sostenibilidad y el desarrollo comunitario, han incrementado los flujos turísticos internacionales en toda la región (Acerenza, 2006: 101).

En la actualidad, América del Sur se alza como el segundo espacio turístico de mayor crecimiento del continente, con un porcentaje en torno al $5 \%$, solamente, por detrás de América Central, con un 7,3\%. Asimismo, la subregión turística recibe un total de 26,7 millones de visitantes internacionales, constituyendo el 16\% del total de llegadas, quedando en segundo lugar, aunque muy alejado del primer puesto, ocupado por América del Norte, con unos 106,7 millones de turistas, que componen el 65\% del total americano (OMT, 2013: 16). Entre otros factores, el incremento del turismo se ha visto favorecido por la mejora de la estabilidad política de la región y un crecimiento económico generalizado, así como el perfeccionamiento de los productos turísticos, la capacitación y formación en cultura turística, y, especialmente, la mejora de las condiciones de accesibilidad terrestre, aérea y marítima.

Dentro de este panorama general, en Colombia, el turismo ha pasado de tener una posición secundaria a ser una actividad creciente, especialmente, durante los últimos 15 años. No obstante, el sector siempre ha tenido una posición marginal en el país, con una reducida participación porcentual en el producto interno bruto, que, en los últimos 30 años, siempre se ha situado entre el 2\% y el 5\% del valor total (Brida et. al., 2011: 292). Ello debido a múltiples factores, como la existencia de un énfasis productivo que ha caracterizado la estructura económica 
nacional, centrado en los sectores agrícolas, manufactureros, extractivistas y de hidrocarburos, y también comerciales, aunque, fundamentalmente, de tipo financiero. Los primeros han supuesto, además, un inconveniente añadido al desarrollo de algunos destinos colombianos, al competir directamente en el uso intensivo de los recursos naturales. De otra parte, la inexistencia, durante mucho tiempo, de un modelo turístico integrado para el país, ha conllevado a que, a pesar de los esfuerzos gremiales e institucionales, la actividad turística haya sido vista más como un "bonito adorno" que como un sector estratégico para el desarrollo regional y nacional del país (Gómez, 2002: 63).

Al mismo tiempo, el turismo se ha visto reducido y limitado por el conflicto armado, desde los años 80, y principalmente, durante toda la década de los 90 (Gómez, 2002: 57; Van Broeck, 2002: 44). La inestabilidad política de este periodo ha condicionado tanto el desarrollo de los destinos turísticos más maduros como aquellos emergentes del país, así como los flujos turísticos emisores y receptivos, tanto domésticos realizados por los colombianos al interior del país -como internacionales- de extranjeros que visitan Colombia. Bajo el conflicto armado colombiano, las áreas rurales - pero también las urbanas- se vieron perjudicadas en el ámbito turístico, y solamente unos pocos espacios reforzaron el número de turistas. Varios componentes han tenido una influencia directa en esta relación, aunque destaca la pérdida de seguridad y la falta de accesibilidad de los destinos y atractivos -especialmente a partir de los movimientos que los distintos frentes han realizado por el territorio colombiano-, así como la incidencia de éstos sobre el estado de las infraestructuras necesarias, y el desarrollo de los diferentes operadores turísticos, llegando todo ello a modificar la imagen turística durante el periodo de violencia armada.

La paz, representa una condición necesaria para el desarrollo y la promoción del turismo en cualquier país (D’Amore, 1988: 38; Litvin, 1998: 64). El fin del conflicto armado en Colombia ha coincidido con un refuerzo institucional del turismo y una mejora en los indicadores económicos del sector, que desde el 2013, y ha conseguido duplicar la cifra de visitantes, posicionando a Colombia como el cuarto destino turístico dentro de la subregión turística de América del Sur (MINCIT, 2016, s.p.). En este sentido, el escenario de posconflicto que se presenta permite repensar el modelo turístico que necesita el país, en el cuál, además de la recuperación estructural y económica, la actividad turística pueda tener un papel en los procesos de reconstrucción social y cultural de los territorios más afectados, siendo, por tanto, el turismo, no sólo un beneficiario de la paz, sino también un instrumento de contribución a ella (Savignac, 1994: s.p). 


\section{Turismo y conflicto: de la inseguridad a la paz}

El turismo tiene la capacidad de impactar en los ámbitos socioeconómicos, culturales y medioambientales, entre otros, pero también puede verse afectado por los elementos contextuales del destino en el que se desarrolla (Leiper, 1979: 398; OMT, 1980: 20; Mathieson y Wall, 1982: 55). En este sentido, el turismo reacciona como una actividad socioeconómica vulnerable, que, ante cualquier indicio de riesgo para el visitante, puede provocar un repliegue o incluso una eliminación de las actividades o flujos turísticos que se estén desarrollando (Burns y Novelli, 2008: 4). Ello incluye hechos políticos o sociales que impliquen violencia, como delincuencia, crímenes, actos terroristas o conflictos armados (Ryan, 1993: 7; Pizam, 2002: 2; Pizam y Mansfeld, 2006: 15; Tarlow, 2006; Schluter, 2008: 147), aunque, no todos ellos revisten de las mismas características. Así, por ejemplo, mientras un ataque terrorista suele ser puntual e impredecible, los conflictos armados se caracterizan por una mayor previsión y prolongación en el tiempo. No obstante, ambos coinciden en que pueden integrar o ser dirigidos hacia el turismo, ya sea por medio de acciones violentas contra la estructura turística -hoteles, vías, aeropuertos, museos, entre otros -o cada vez más, contra el propio turista- secuestros, atentados- debido al valor simbólico y repercusión que estas acciones pueden llegar a tener (Ritcher y Waugh, 1986: 231). Igualmente, las consecuencias pueden darse tanto en el momento en el que ocurren, como dilatarse durante los periodos posteriores al mismo (Cavlek, 2002: 470; Pizam y Mansfeld, 2006: 16).

Los destinos turísticos que se encuentran bajo conflicto armado suelen estar condicionados, por la percepción de inseguridad que se tiene de ellos, siendo este elemento básico y determinante para el desarrollo del turismo (Fuchs y Pizam, 2011: 302). Esto, porque la consideración de inseguro por parte un turista, operador turístico u otro actor con relación directa o indirecta con el turismo, incide sobre la imagen del destino. A su vez, esta circunstancia puede disminuir el flujo turístico (Pizam, 1999: 6; Mawby, 2000: 113; Araña y León, 2008: 302), repercutiendo en el resto de actores turísticos y no turísticos, incluyendo la comunidad residente, en el lugar de acogida, por lo que, como señala, Steene (1999: 13) un conflicto armado condiciona a todos los elementos del sistema turístico. Incluso cuando el destino presente un gran potencial y diversidad de atractivos turísticos, una planta turística adecuada o eficientes campañas de promoción turística, no competirá de manera satisfactoria en los mercados turísticos en los que se inserte (Fuchs y Pizam, 2011: 302).

De hecho, los mercados emisores analizan los riesgos que implica viajar a territorios con conflicto armado o actos violentos en general, y realizan instrucciones a determinados destinos, que son formulados, entre otros, por los diferentes ministerios de asuntos exteriores o cancillerías, pero también desde 
los medios de comunicación, alertando sobre aquellos países que presenten algún tipo de amenaza (Drabek, 2000: 352; Lepp, y Gibson, 2003: 613). Si bien estas indicaciones suelen ser recomendaciones $-\mathrm{y}$ por tanto no vinculantestienen una incidencia alta sobre la decisión de los turistas. Estas pautas también pueden ser emitidas por otros actores, como las agencias de viajes minoristas, y en los últimos tiempos, las páginas web y blogs de viajes (Cavlek, 2002: 480). Además, los operadores turísticos emisores, también analizan los riesgos que conllevan la inclusión de estos territorios dentro de los paquetes turísticos que crean, buscando garantías para los clientes, ya que, de una parte, los prestadores son, generalmente, los responsables subsidiarios, y de otra, cualquier evento negativo puedes afectarles directamente en su rendimiento e imagen (Drabek, 2000: 353). Por lo tanto, la no programación, omisión o cancelación de un destino particular por parte de un operador turístico también indica que el destino no es considerado seguro, y el turista, en su libertad de elección, prefiere viajar a destinos sustitutivos que ofrezcan una mayor estabilidad política, hasta que la situación del destino en conflicto se resuelva de manera satisfactoria o definitiva (Lepp y Gibson, 2003: 605).

Aun con todo, un destino que sufre algún tipo de inestabilidad política no significa que no sea visitable. A nivel mundial existen países que, estando en dicha situación, han llegado a recibir o reciben niveles medios o incluso altos de turismo, aunque en ocasiones, estos flujos se concentren en unos pocos espacios turísticos que son los que ofrecen mayores garantías y seguridad al visitante (Sönmez, 1998: 417; Lepp, y Gibson, 2003: 613). Así, destacan países ubicados en África y Oriente Medio, como Túnez, Egipto, Turquía, Siria o Israel, éste último con un desarrollo turístico importante en un contexto de violencia prolongada en el tiempo (Mansfeld, 1996: 267; Beirman, 2002: 167). En Asia, igualmente, se encuentran países que han experimentado o experimentan flujos turísticos en escenarios de inestabilidad política, como Vietnam, o Sri Lanka, el cual se ha alzado como uno de los países con mayor crecimiento de la actividad turística en el continente tras el fin de su conflicto bélico (Keyes, 2012: 3). En Latinoamérica, Perú es citado como un destino en el que la violencia ejercida por el grupo armado Sendero Luminoso, causó, entre 1989 y 1991 , un declive drástico en el turismo (Wahab, 1996: 355), mientras que el crimen y el narcotráfico son vistos como obstáculos para el turismo tanto en Colombia como México, aunque, paradójicamente, el segundo ocupe el primer puesto en nivel de llegadas internacionales (Santana, 2001: 13).

No obstante, si un destino afectado por el terrorismo o el conflicto armado puede representar dudas para su desarrollo, la resolución o finalización del mismo también plantea incertidumbres. De este modo, aunque la paz se considera como una condición necesaria para el turismo (Pratt y Liu, 2016: 83), la paz, por sí misma, es un concepto complejo y de difícil consenso, por lo que 
su vinculación con el turismo será necesariamente complicada. Así, atendiendo a Galtung (1969) la paz puede ser entendida como negativa, es decir, mediante la ausencia de guerra y/o violencia, y positiva, que se caracteriza mediante la colaboración y construcción conjunta de un entorno de paz duradero. En este sentido, como reconocen Causevic y Lynch (2013: 155), la paz negativa, aunque reconoce la ausencia de conflicto armado y de violencia directa, y, por tanto, es un punto de partida necesario, no reúne las suficientes garantías para un desarrollo turístico pleno, ya que mientras aspectos como seguridad o accesibilidad pueden ser mejorados, otros elementos turísticos solamente se establecerán de manera completa en un clima de paz positiva. Sea como fuere, destinos como Irlanda del Norte, suelen mostrarse como ejemplos de la coincidencia entre el desarrollo turístico e implementación de los acuerdos de paz - paz negativa-, pues mientras que el estadillo del conflicto generó una disminución drástica de la afluencia de visitantes, (Anson, 1999: 60) los consiguientes ceses del fuego, a finales de la década de 1990, provocaron un aumento en la llegada de turistas y en la inversión tanto de las infraestructuras públicas como de los atractivos turísticos (Leslie, 1996: 52). Por el contrario, si se atiende a los países centroamericanos, como modelos similares al conflicto colombiano en lo que respecta a la resolución de sus conflictos, únicamente Guatemala ha desarrollado cierta actividad turística (Bassols, 2016: 318).

A la hora de analizar cómo la paz puede contribuir al desarrollo turístico, y superar los aspectos negativos que conllevan estos periodos de inestabilidad, es necesario algo más que acciones dirigidas a la mejora de la seguridad e imagen turística (Somnez, Apostolopoulos y Tarlow, 1999: 15). No se trata de promocionar un escenario en el cual ya no existen riesgos o actos violentos, sino que es necesario establecer un proceso de recuperación integral, con un rol proactivo de todo el sector público y privado con o sin injerencia, así como los actores turísticos y la comunidad, además de los operadores nacionales e internacionales, lo que ha sido conceptualizado, como Phoenix Tourism por autores como Causevic y Lynch (2011: 780).

Esta tipología turística contempla, entre otras acciones, que el factor social ocupe un rol esencial, especialmente, en lo referente a la inclusión social por medio de la implicación activa de las comunidades. Para ello se fomenta la visita turística a espacios y zonas de importancia durante el conflicto armado, integrando a los actores armados, especialmente, las guerrillas y otros colectivos estigmatizados y vulnerables a través de actividades o emprendimiento turísticos -vinculados con procesos comunitarios y sostenibles. De esta forma, se pretende la reducción de las percepciones y estereotipos negativos, así como la búsqueda de comprensión y respeto mutuo entre residentes y turistas (Akjellerud, 2003: 42; Tomljenovic, 2010: 19; Causevic y Lynch, 2011: 788). 
Desde esta perspectiva, la generación de desarrollo también pasa por el papel que juegan los operadores y empresas turísticas, y la inserción de los destinos en posconflicto dentro de los mercados nacionales e internacionales, labor que debe ser desempeñada de manera conjunta y coordinada desde las acciones de comercialización y promoción, pero que, en cualquiera de los casos, sirva para reforzar los mensajes de comprensión y de paz (Moufakkir y Kelly, 2010: 20). Esto es aplicable al resto de actores turísticos implicados, puesto que, si no se fomentan este tipo de pautas, existe una alta probabilidad de que el turismo pueda crear divisiones entre actores y residentes, o, peor aún, que se genere una batalla por los recursos escasos, generando una mayor rivalidad entre los diferentes sectores sociales, llegando, incluso, a fenómenos de exclusión y expropiación (Scott, 2012).

Ello también afecta al desarrollo y fortalecimiento de productos turísticos, ya que un territorio en posconflicto implica que el turismo pueda aprovechar el potencial significado histórico del conflicto que hubo, mediante el desarrollo de tipologías turísticas como el Dark Tourism -Turismo Negro- o el Turismo de la Memoria (Anson, 1999: 62). Así, existe la posibilidad de integrar el conflicto dentro del mercado turístico del país, o también, en el sentido contrario, aplicar una "amnesia colectiva" que invisibilice esa parte de la historia - como ha sucedido en los casos de Sri Lanka o Guatemala (Bassols, 2016: 318). Según Velásquez et al. (2014: 110) esta última opción es más sencilla, pues "es más difícil para los territorios aceptar un pasado negativo reciente - por no hablar de mostrarlo ante los visitantes o usarlo como herramienta de promoción - que consignarlo al olvido". De hecho, un uso exclusivo del conflicto por parte del turismo puede reducir el perfil de turista potencial, ya que se centraría solamente en un único tipo de mercado, reduciendo las posibilidades que otros atractivos u otras tipologías turísticas -recuperadas o nuevas- podrían aportar al destino.

Sea como fuere, la infraestructura turística también debe ser atendida en el periodo de posconflicto, pues tanto actos terroristas como conflictos armados pueden haberla dañado, siendo necesaria su restauración o su reconstrucción, así como el establecimiento o restablecimiento de la conectividad -vial, marítima, aeropuertos- o de otros servicios como el tendido eléctrico, el agua, las telecomunicaciones, etc. y que inciden en la accesibilidad turística (Drabek, 2000: 355). Finalmente, todos estos aspectos deben ser reforzados y articulados dentro de un marco político, ya que según Litvin (1998: 62) y Causevic y Lynch (2011: 782) el potencial turístico de un territorio en posconflicto es limitado si el apoyo gubernamental no apoya por igual a todos los actores y grupos implicados. Dentro de este aspecto, es necesario no sólo políticas u acciones marcadas por las instituciones vinculadas con el turismo, sino con aquellos otros que puedan interferir en el sector, como asuntos exteriores, transporte, cultura, economía, etc. 
La paz es una condición necesaria para el turismo, pero también la actividad turística puede ser un instrumento para su desarrollo, siempre y cuando las actividades se encaminen hacia la sostenibilidad, e impliquen más ámbitos del estrictamente económico (Anson, 1999: 60; Prat y Liu, 2016: 89). En esa línea se han encaminado instituciones internacionales como la Organización Mundial del Turismo - OMT, que en sus propios estatutos señala que el objetivo del turismo es contribuir al "desarrollo económico, la comprensión internacional y la paz" (OMT, Art. 3.), aspecto que ha intentado refrendar en muchas de sus declaraciones, como la Carta del Turismo y Código del Turista (1985); el Código ético mundial para el turismo (1999) y la Declaración de Ammán sobre la paz mediante el Turismo (2000). Asimismo, la OMT, en el año 2015, celebró, su Asamblea General en Medellín, dedicando, entre otros aspectos, un énfasis al turismo como vehículo de paz, y señalando, a través del secretario general de la organización, el papel clave que este sector debe tener en el proceso de posconflicto colombiano (MINCIT, 2015, s.p.).

\section{Turismo en Colombia: del conflicto armado al posconflicto}

Los primeros datos sobre turismo en Colombia se remontan, de un lado, a la promoción a través de las secciones de información y propaganda del país por parte de los consulados colombianos, en el año 1911, y a la creación del Servicio Oficial de Turismo, en el año 1931, considerado este hecho como la primera manifestación expresa de interés por la actividad turística del país (Toro, 2003: 11, Brida et. al., 2009: 24). No obstante, se desconoce el número de visitantes que Colombia podía tener en aquella época, aunque ya se empezaban a erigir algunos de los hoteles más emblemáticos del país, como el Hotel Caribe, en Cartagena de Indias, inaugurado en el año 1945. En los albores de la década de los años 50, se constituye el primer gremio turístico, la Asociación Colombiana de Agencias de Viaje y Turismo - ANATO- y, tan solo seis años después, lo hace ACOTEL -Asociación Colombiana de Hoteles, rebautizada, desde los años 80 como COTELCO- y que, en un principio, ya integraba unos 70 hoteles en todo el territorio.

En el año 1957, el gobierno de la república creó la Empresa Colombiana de Turismo, que tendría una duración de 10 años, período en el que se desarrollarían algunas de las iniciativas turísticas más representativas; en 1959 se estrena el Aeropuerto Internacional de El Dorado, con el objetivo de duplicar sus operaciones y convertirse en un nodo de conectividad en América Latina; en 1963 se inaugura el Hotel Irotama en Santa Marta, considerado el primer resort del país. De este modo, en el año 1966, el número de turistas extranjeros se situaba en torno a los 66.000, cifra que aumentará en los 
siguientes cinco años, hasta alcanzar los 95.000 visitantes internacionales (Caro y Bula, 1998: 65).

Dos años más tarde, en 1968, se crea el nuevo órgano competente en materia turística, denominado Corporación Nacional de Turismo (CNT) y que adelantó una importante labor de impulso del turismo en el país (Toro, 2003: 11). Entre los objetivos de esta institución, que se mantuvo vigente hasta el año 1997, estaba la planeación, regulación, control, financiación y promoción turística. Según Jaramillo (2006: 20), Colombia tuvo una posición de partida muy buena para el desarrollo turístico durante la década de los años sesenta y setenta, en comparación con otros países de la región, ya que contaban con una conectividad aérea muy buena, y, además, con unas infraestructuras en buenas condiciones, destacando la creación de numerosos centros de congresos y convenciones en el país, como el de Cartagena de Indias, que, permitía posicionar al país dentro del turismo MICE. Asimismo, durante la década de los años 70, el país favoreció la creación de productos turísticos de sol y playa, principalmente, en la costa atlántica colombiana, encumbrando a destinos como Cartagena de Indias o Santa Marta e, incluso, creándose nuevos desarrollos, siendo El Rodadero el caso más destacado de todos. De este modo, durante este periodo, tanto el turismo receptivo como emisor crecía de manera estable, pasando de 161.000 turistas internacionales a 1.227.700, y produciéndose incrementos porcentuales en torno al 30\% durante los años 1974, 1977 y 1979 (Tabla 1).

Tabla 1. Llegadas internacionales, periodo baja - media intensidad conflicto armado

\begin{tabular}{|c|c|c|c|c|c|c|c|c|c|c|}
\hline Ã̃) & 1970 & 1971 & 1972 & 1973 & 1974 & 1975 & 1976 & 1977 & 1978 & 1979 \\
\hline $\begin{array}{l}\text { Turistas } \\
\text { (miles) }\end{array}$ & 161,7 & 197,5 & 229,1 & 274,8 & 362,9 & 443,2 & 522,1 & 708,6 & 826,3 & 1116,7 \\
\hline Variación \% & 13,4 & 22,1 & 16,0 & 19,9 & 32,1 & 22,1 & 17,8 & 35,7 & 16,6 & 35,1 \\
\hline AÑNO & 1980 & 1981 & 1982 & 1983 & 1984 & 1985 & 1986 & 1987 & 1988 & 1989 \\
\hline Turista (miles) & 1227,7 & 1059,6 & 1082,4 & 506,8 & 715,3 & 784 & 732,2 & 541,2 & 828,8 & 733 \\
\hline Variación \% & 9,9 & $-13,7$ & 2,2 & $-53,2$ & 41,1 & 9,6 & $-6,6$ & $-26,1$ & 53,1 & $-11,6$ \\
\hline
\end{tabular}

Fuente: Quinto (2009: 15)

La situación cambia durante los años 80 aunque, según Jaramillo (2006: 8), el impulso turístico del país se ve frenado, en un primer momento, por la mala gestión, el narcotráfico y la corrupción, ya que el conflicto armado no era tan determinante, y por tanto la intensidad del mismo podía considerarse baja o media, si bien ya empezaba a condicionar algunas prácticas turísticas nacionales e internacionales, y la seguridad, a finales de la década, ya empezaba a percibirse como un impedimento para la realización de viajes por el país (Bassols, 2016: 318). De hecho, atendiendo a la anterior tabla, el número de turistas se redujo 
de manera considerable, con un descenso acusado entre los años 1983 y 1987, y, para finales de la década, cuando la afluencia se había reducido casi a la mitad. A nivel institucional, la labor de la Corporación Nacional de Turismo prosiguió, realizando campañas de concientización como "turista satisfechos trae más turistas", que ahondaban en la necesidad de trasmitir una visión amable por parte de la población receptora. De igual manera, en el año 1984, se crean los fondos mixtos de promoción turística, como acción para el fomento de la inversión en el sector, y que, posteriormente, serían integrados bajo el Fondo de Promoción Turística - FONTUR.

En general, durante esta década las iniciativas vinculadas con el turismo prosiguieron, creándose nuevos productos turísticos nacionales, como, por ejemplo, el desarrollo de actividad turística naturales o ecológicas, como la inclusión de los Parques Naturales Nacionales del país, que, durante estos años fueron promocionados coincidiendo con las políticas de ecoturismo emanadas por la Conferencia de Rio de Janeiro (Mapa 1). 
Mapa 1. Principales destinos y atractivos turísticos en Colombia

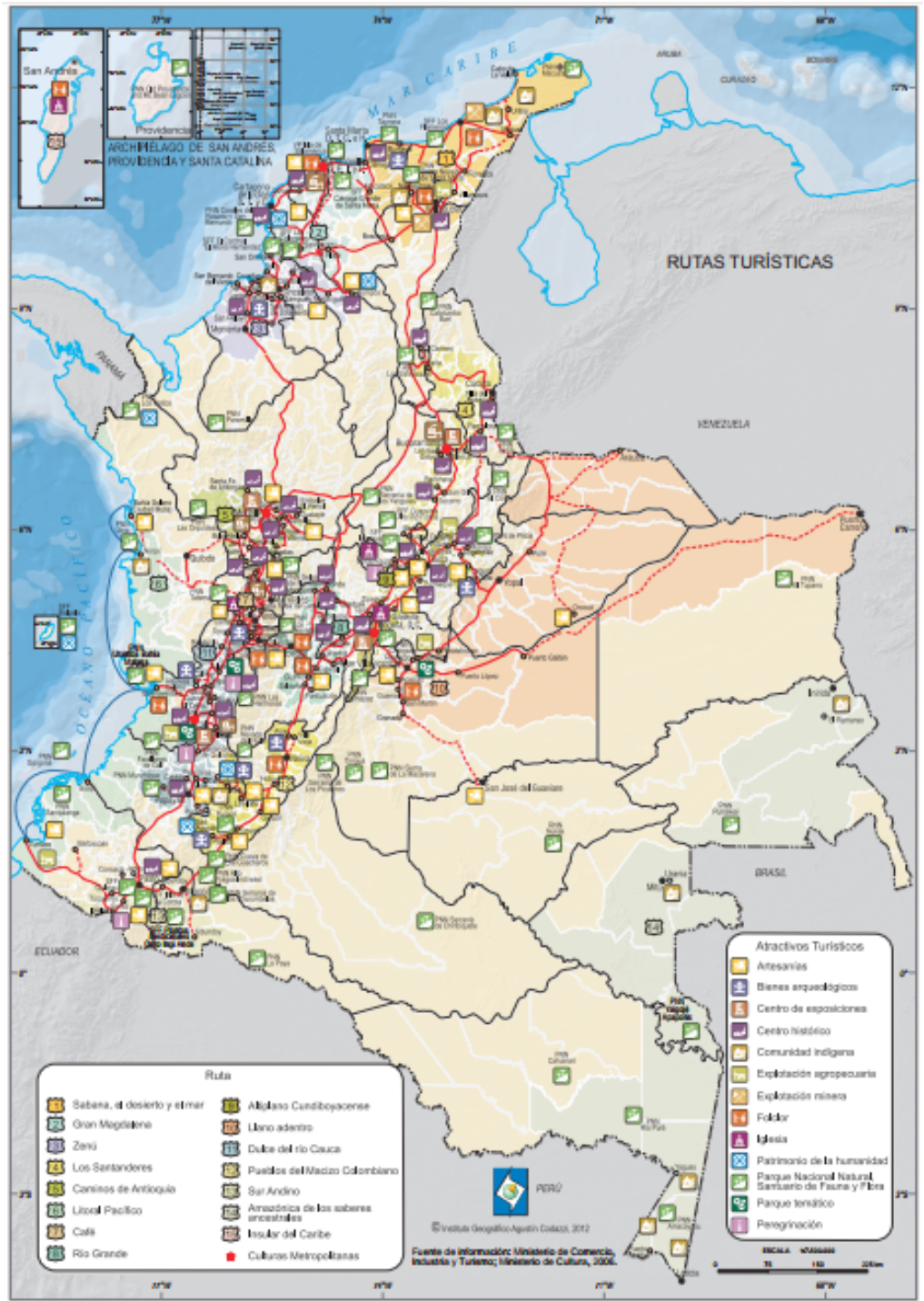

Fuente: Instituto Agustín Codazzi, 2006.

También, durante los años 90, se favoreció el Eje Cafetero, ya que la crisis del café, iniciada a partir del año 1989, obligó a la búsqueda de una reconversión de las fincas cafeteras en espacios recreativo para el ocio y el alojamiento 
turístico, especialmente, en los departamentos del Quindío, Risaralda, Caldas y algunas zonas del sur de Antioquía (Broeck, A.M., 2002: 45). Igualmente, la declaratoria como Patrimonio de la Humanidad por la UNESCO de diferentes espacios naturales -como Los Katíos-, culturales -Mompox, San Basilio Palenque- y arqueológicos -San Agustín y Tierradentro- permitieron reconocer e incluso posicionar a estos espacios dentro del mapa turístico del país. No obstante, todos estos productos y destinos se van a seguir viendo opacados por el desarrollo del turismo de sol y playa en la región Caribe, que seguirá siendo la tipología que más turistas nacionales e internacionales registrará durante la década. De este modo, Cartagena de Indias, Santa Marta y San Andrés se mantendrán como destinos preferentes, aunque se seguirán desarrollando otros destinos atlánticos similares como Coveñas y Tolú (Van Broeck, A.M, 2002: 45).

Con el incremento de la violencia durante la década de los 90, el turismo en Colombia sufrió una contracción sin precedentes (Rozo y Garavito, 2014: 28). En este sentido, el turismo colombiano, al igual que otras actividades productivas y económicas del país, se vio afectado, de manera colateral por la pérdida de seguridad y competitividad (López, 2001: 6). Esta última fue analizada por el gobierno de Samper, que realizó un informe de competitividad del sector y creó la Ley 300, de 1996, general de Turismo, que supuso el inicio de un refuerzo institucional para el sector (Toro, 2003: 11).

No obstante, los datos turísticos obtenidos demuestran una tendencia decreciente, tanto en los flujos turísticos nacionales e internacionales, como en su aportación al producto interior bruto (PIB) del país. Así, durante esta década, el sector turístico representó unos ingresos del $20-30 \%$ de las exportaciones totales realizadas, lo que representaba alrededor de un 2,5\% del PIB, cifra que descendió al 2\% a finales de la década y que fue especialmente notorio entre los años 1996 y 1997 (Brida et. al. 2009: 17). Si se atiende al número de llegadas, se pueden observar tres años con variaciones negativas importantes; el año 1993, con un $-2,7 \%$ de llegadas, el año 1996, en el que los flujos internacionales se redujeron un 54,9\% respecto al anterior año-pasando de los 1.398 .000 turistas a los $630.500-y$, finalmente durante el año 1999, en el cual el número de turistas volvió a decrecer en un 19\%, siendo el flujo total de turista para finales de la década de poco más de medio millón (Tabla 2). 
Tabla 2. Llegadas internacionales y crecimiento, periodo media - alta intensidad conflicto armado

\begin{tabular}{|c|c|c|c|c|c|c|c|c|c|c|}
\hline AÑO & $\mathbf{1 9 9 0}$ & $\mathbf{1 9 9 1}$ & $\mathbf{1 9 9 2}$ & $\mathbf{1 9 9 3}$ & $\mathbf{1 9 9 4}$ & $\mathbf{1 9 9 5}$ & $\mathbf{1 9 9 6}$ & $\mathbf{1 9 9 7}$ & $\mathbf{1 9 9 8}$ & $\mathbf{1 9 9 9}$ \\
\hline $\begin{array}{c}\text { Turistas } \\
\text { (miles) }\end{array}$ & 812,8 & 856,9 & 1075,9 & 1047,3 & 1206,9 & 1398,5 & 630,5 & 639,3 & 674,4 & 546 \\
\hline Variación \% & 10,9 & 5,4 & 25,6 & $-2,7$ & 15,2 & 15,9 & $-54,9$ & 1,4 & 5,5 & $-19,0$ \\
\hline PIB \% & 2,59 & 2,62 & 2,61 & 2,52 & 2,47 & 2,48 & 2,30 & 2,10 & 2,11 & 2,07 \\
\hline
\end{tabular}

Fuente: Quinto (2009: 10) y Brida et. al. (2009: 17).

Esta época coincide con el aumento de las ofensivas armadas por parte de las FARC y el ELN, al mismo tiempo que se creaban y se incrementaba los grupos paramilitares, lo que aumentó la presencia del conflicto armado en numerosos espacios colombianos, coincidiendo alguno de ellos con los destinos y productos turísticos anteriormente mencionados ${ }^{2}$. Así, las iniciativas ecoturísticas señaladas con anterioridad, especialmente las vinculadas con los Parques Naturales Nacionales, perdieron buena parte de sus flujos, en especial, aquellos ubicados en la región amazónica y, concretamente, en Sierra Nevada de Santa Marta (Bolívar) y el Cocuy (Boyacá y Arauca), además de otros destinos naturales que se estaban revalorizando como Nuquí, Turbo y Bahía Solano, todos ellos en el departamento del Chocó. También los citados parques arqueológicos de San Agustín y Tierradentro se vieron afectados, principalmente debido a la accesibilidad de los mismos, ya que la vía de acceso a los mismos desde Neiva presentaba altos riesgos, lo que redujo el número de visitantes ${ }^{3}$.

Ya casi en la década de los años 2000, destinos como la Sierra de la Macarena (Meta), donde se ubica uno de los principales atractivos del país, como es Caño Cristales, así como parques como el Tayrona (Magdalena), Los Katíos (Antioquía y Chocó), El Puracé (Cauca), Los Farallones (Valle) y los nevados ubicados en el eje cafetero fueron considerados lugares en zona de riesgo, lo que ahuyentó a los turistas (Van Broeck, A.M, 2002: 52). Además, en los periodos de mayor conflicto armado, zonas de valor ecológico ubicadas en

\footnotetext{
${ }^{2}$ Durante esta época también se aumentaron los secuestros de personas extranjeras, en su mayoría residentes, pero también turistas. Estos se desarrollaban por medio de retenes y "pescas milagrosas" en los accesos, pero también en algunos establecimientos turísticos. Así, para el primer caso, las infraestructuras de la zona antioqueña y la costa atlántica se vio afectada por bloqueos y atentados, por ejemplo, en las vías Medellín - Cartagena, y en los accesos a Tolú y Coveñas, debido, principalmente, a la presencia paramilitar en Córdoba (Ríos, 2017). En el año 1999, el ELN secuestró un vuelo de Avianca entre Santander y Bucaramanga, y el retiro de la fuerza pública en Capurganá, en el año 2000, provocó la cancelación todas las rutas comerciales aéreas a la zona. Respecto a los secuestros, en el año 2001, un grupo guerrillero secuestró a varios huéspedes del alojamiento Barandú (Antioquía), así como se revindicó una bomba en el hotel Torre de Cali (Valle) (Van Broeck, A.M., 2002: 47 - 48).

${ }^{3}$ Además de las vías, también se vieron afectadas otras infraestructuras, como el alumbrado, que sufrió diversos atentados en las torres de energía (Van Broeck, A.M., 2002: 47).
} 
el departamento de Cundinamarca y en los alrededores de Bogotá, tuvieron que cancelar las rutas y caminatas de índole turístico por problemas de seguridad, como en Sumapaz, Guasca o Chingaza (Cundinamarca). Dentro de los destinos urbanos, ciudades como Popayán, Cali o Medellín fueron señalados como peligrosas por las agremiaciones turísticas como ANATO.

Por el contrario, el conflicto colombiano reactivó o potenció aquellos espacios turísticos cuyos accesos y situación interna no presentaban riesgos, particularmente, los destinos maduros de la zona Atlántica, como Cartagena de Indias, Santa Marta, San Andrés y, adicionalmente, el Eje Cafetero. De este modo, las dos primeras se mantuvieron como los principales destinos internacionales, dado su fácil acceso por vía marítima y aérea -aunque perdieron turistas nacionales, pues los accesos por tierra seguían siendo peligrosos- y solamente el Eje Cafetero se mantuvo como el único territorio interno del país con continuidad turística durante este periodo (Van Broeck, A.M., 2002: 51; Gómez, 2002: 65).

Esta situación continúo hasta los primeros años de los años 2000. Los problemas de inseguridad y accesibilidad que atravesaban los destinos del país se sumaron a una mala imagen turística de Colombia en el exterior, especialmente por parte del mercado estadounidenses, y en menor medida, el europeo, lo que conllevó a que, durante estos primeros años, su principal flujo, estuviera conformado, en su mayor parte, por el turismo doméstico, e incluso éste presentará dificultades (López, 2001: 5). Para contrarrestar estos aspectos, durante el gobierno de Pastrana se formuló la "política turística para una sociedad que construye la paz", que buscó fortalecer el sector a partir de un plan estratégico donde la seguridad era un eje principal, aunque también se procedió a un seguimiento más continuado de las instituciones regionales de turismo y de los subsectores turísticos, en un intento por mantener un sistema turístico más integrado (Toro, 2003: 11). Posteriormente, en el año 2002, se elabora el programa de promoción turística "Vive Colombia, viaja por ella" como medida para promover el turismo nacional por vía terrestre. Dentro del mismo, se desarrolla la iniciativa "Caravanas turísticas" que organiza convoyes de vehículos a diferentes destinos dentro del país, en días feriados y fines de semanas, principalmente en el entorno andino -Cali, Pereira, Pasto, Medellín, como atlántico- Santa Marta, Cartagena de Indias, Barranquilla, entre otros (Política de Turismo Cultural, 2007: 15). Para ello, la Policía y las Fuerzas Armadas escoltaban a los vehículos, intensificándose la vigilancia en las vías, lo que hizo posible que se mejorase la percepción de seguridad y aumentase el uso de autobuses y vehículos particulares. También, se favoreció una mayor accesibilidad a los destinos que ofrecían inseguridad en sus vías de acceso. Según Ojeda (2013: 775) esta iniciativa, que hacía parte de la política de Seguridad Democrática del gobierno de Álvaro Uribe, tuvo un efecto positivo 
en el turismo, aunque basado, exclusivamente, en la hipervigilancia y en la militarización de las vías.

En cualquier caso, estas iniciativas coincidieron con un cambio de tendencias, evidenciado a través de los indicadores turísticos del país. Si desde 1999 a 2004, las llegadas internacionales mostraban un ritmo decreciente del sector, a partir del año 2004, se experimenta una variación en el número de turistas internacionales, aumentando en un 25,3\%. Aunque este incremento se desaceleró en los siguientes años, el número de turistas totales aumentó de manera paulatina, llegando a finales de la década de los 2000, a recibir un total de 1.353.800 millones de turistas. De igual manera se si se atiende al PIB, mientras que, en el año 2000 la contribución al mismo era del 2,08\%, al final de la misma década, el porcentaje había crecido de manera sostenida hasta el 2,79\% (Tabla 3).

Tabla 3. Llegadas internacionales y crecimiento, periodo alta - baja intensidad conflicto armado

\begin{tabular}{|c|c|c|c|c|c|c|c|c|c|c|}
\hline AÑO & $\mathbf{2 0 0 0}$ & $\mathbf{2 0 0 1}$ & $\mathbf{2 0 0 2}$ & $\mathbf{2 0 0 3}$ & $\mathbf{2 0 0 4}$ & $\mathbf{2 0 0 5}$ & $\mathbf{2 0 0 6}$ & $\mathbf{2 0 0 7}$ & $\mathbf{2 0 0 8}$ & $\mathbf{2 0 0 9}$ \\
\hline $\begin{array}{c}\text { Turistas } \\
\text { (miles) }\end{array}$ & 557,3 & 615,7 & 541,7 & 624,9 & 783,1 & 933,2 & 1053,3 & 1195,4 & 1223 & 1353,8 \\
\hline Variación \% & 2,1 & 10,5 & 12,0 & 15,4 & 25,3 & 19,2 & 12,9 & 13,5 & 2,3 & 10,7 \\
\hline PIB \% & 2,08 & 2,11 & 2,18 & 2,20 & 2,19 & 2,21 & 2,73 & 2,76 & 2,77 & 2,79 \\
\hline
\end{tabular}

Fuente: Quinto (2009: 15) y DANE - OEE - MINCIT (2017: s.p)

De este modo, la década de los años 2000, supuso, cuando menos, un cambio en las tendencias, así como un periodo de recuperación del turismo (Zúñiga - Collazos, 2015: 1; Rozo y Garavito, 2014: 32). Este crecimiento se vio favorecido por un conjunto de políticas estatales, tanto de índole turístico como no turístico, siendo la primera vez en la cual el turismo se estructuraba en torno a un Plan Sectorial de Turismo, y entraba a formar parte del Plan Nacional de Desarrollo del país (Toro, 2003: 12). De igual forma, en el año 2006, se crea el nuevo Viceministerio de Turismo, como órgano competente en el sector y dependiente del Ministerio de Comercio, Industria y Turismo, y se reforma la anterior Ley 300 de Turismo de 1996, destinándose más recursos directos para el sector e incrementándose los incentivos y beneficios fiscales para la inversión extranjera y nacional. También se realizan diferentes Normas Técnicas Sectoriales, encaminadas a la mejora de estándares de calidad de los diferentes sectores turísticos.

En lo referente a la promoción, durante este periodo, se encaminará a los productos prioritarios tanto domésticos como internacionales ya señalados, dando prioridad a los mercados emisores fronterizos de Venezuela, Ecuador y Panamá (Toro, 2003: 12). Además del fortalecimiento institucional, se sigue intentando 
mejorar las condiciones de seguridad para los viajeros (Brida et. al. 2009: 26). En el año 2009, ya existían alrededor de unas 200 "rutas seguras" lo que siguió posibilitando que el turismo doméstico se incrementase a partir de la mejora de percepción de la seguridad. El gobierno intentó reactivar los consejos regionales de seguridad turística, para intentar mantener una coordinación más eficiente entre el sector turístico, los departamentos, la Policía y las Fuerzas Militares.

No obstante, el turismo internacional seguía presentando dudas respecto al país, por ello, se creó y lanzo la campaña internacional "Colombia, el riesgo es que te quieras quedar" (2008) que abogaba por convertir y presentar "el riesgo" -el principal inconveniente para el viajero- en algo positivo, y para ello, se utilizaron relatos de turistas extranjeros que habían decidido radicarse en el país tras su visita. Según Bassols (2016: 316) esta iniciativa, junto con la campaña nacional "Colombia, el país que es parte de tu corazón” consiguieron estabilizar la imagen del país, frenando los efectos negativos que se seguían amplificando a través de los medios de comunicación de masas. La mejora de resultados a nivel nacional e internacional culminó con el documento emitido por la Organización Mundial del Turismo "Colombia, de vuelta en el mapa del turismo mundial" (OMT, 2009) desde el que se señalaba que el país había "logrado volver del borde del abismo" y que, mediante las acciones de seguridad emprendidas y las estrategias coordinadas a nivel institucional, estaba consiguiendo salir de una etapa traumática (OMT, 2009: 22).

A las puertas de las negociaciones del gobierno con la guerrilla de las FARC, el turismo colombiano se presentaba con un refuerzo institucional y un crecimiento constante, dado que el ingreso de turistas se había duplicado en una década y sobrepasado los 2.000.000 para el año 2014 (Tabla 4).

Tabla 4. Llegadas internacionales y crecimiento, periodo baja intensidad conflicto armado

\begin{tabular}{|c|c|c|c|c|c|c|c|c|}
\hline Ã̃ & $\mathbf{2 0 1 0}$ & $\mathbf{2 0 1 1}$ & $\mathbf{2 0 1 2}$ & $\mathbf{2 0 1 3}$ & $\mathbf{2 0 1 4}$ & $\mathbf{2 0 1 5}$ & $\mathbf{2 0 1 6}$ & $\mathbf{2 0 1 7}$ \\
\hline Turistas (miles) & 1404,6 & 1496,4 & 1591,1 & 1726,3 & 1967,8 & 2288,3 & 2593,0 & 2887,5 \\
\hline Variación \% & 8,9 & 7,3 & 7,0 & 8,2 & 12,0 & 16,0 & 13,0 & 11,3 \\
\hline PIB \% & 2,82 & 2,75 & 2,75 & 2,76 & 2,78 & 2,86 & 2,85 & $2,13 *$ \\
\hline
\end{tabular}

Fuente: Quinto (2009: 15) y DANE - OEE - MINCIT (2017: s.p)

No obstante, estos indicadores turísticos aún no permitían ubica a Colombia como un destino americano representativo (Brida et. al, 2009: 18) pero si como un importante factor de cambio en el país, que, conforme a la posible finalización del conflicto armado, auguraba la mejora de los niveles de seguridad, accesibilidad e imagen internacional; crecimiento económico derivado del efecto multiplicador del turismo, y cada vez más, ser un vector de desarrollo que pueda generar territorios de paz (Gómez, 2002: 65; MINCIT: 2014: 6). 


\section{Acuerdo de Paz en Colombia: Nuevos escenarios para el turismo}

La firma del Acuerdo de Paz entre el gobierno colombiano y las FARC, a finales de 2016, ha tenido una influencia en el crecimiento del turismo, materializada en el incremento de más de un $27 \%$ del número de llegadas internacionales desde que dio comienzo el periodo de posconflicto, lo cual es consecuencia de la mejora de la seguridad y promoción internacional, principalmente, aunque también de las iniciativas en capacitación y mejora de los servicios prestados (Jaramillo, 2018, s.p).

Sin embargo, según los informes de competitividad, el sector turístico en el país sigue presentando una serie de problemas, muchos de ellos resultado de la propia inestabilidad política (Brida et. al., 2009: 16). Entre las principales debilidades se sigue encontrando una conectividad deficiente -especialmente la terrestre, que necesita pavimentación y ampliación de numerosas vías- y una alta informalidad en el sector. Así, y a pesar de las mejoras señaladas por el gobierno, la seguridad sigue siendo una preocupación, y también la descoordinación entre las políticas públicas de turismo y los territorios, especialmente en la escala regional, en las cuáles se aprecia todavía una desarticulación entre el sector público y privado.

Además, el conflicto armado colombiano ha dejado a los destinos y atractivos turísticos del país en una situación muy asimétrica. De un lado, se encuentran territorios que, aun conviviendo con el conflicto armado, siguieron funcionando como destinos turísticos, como San Andrés, la costa Atlántica y el Eje Cafetero; seguidamente, se encuentran aquellos espacios y territorios que, tras haber desarrollado una incipiente actividad turística, ésta se vio interrumpida durante el conflicto colombiano, con un mayor o menor grado de deterioro de las estructuras necesarias para recuperar la actividades turística, y entre los que se encontraría ciertos espacios del departamento del Chocó, Antioquía, Santander, Huila y Tolima, y, en general, la mayor parte de los espacios naturales del país. Finalmente, están aquellos territorios que nunca tuvieron iniciativas turísticas, pero que, en el nuevo escenario de posconflicto consideran al turismo como un sector económico que les posibilita crecimiento y desarrollo.

Para ello, el país ha establecido un marco legal para el turismo en el escenario de posconflicto, que contemplan tanto aspectos comunes a todos los destinos, como una línea de actuación específica para aquellos espacios turísticos que hayan sido afectados por el conflicto armado, en los que el turismo se ha considerado como un "bálsamo" para cicatrizar las heridas producidas (Bassols, 2016: 322). De este modo, el Plan de Desarrollo Nacional (2014 - 2018)", en línea con el Plan Sectorial de Turismo "Turismo para la Construcción de la Paz (2014 - 2018)" estructura, para el desarrollo común, 
varios ejes estratégicos y/o temáticos vinculados con la competitividad, la capacitación -educación, la seguridad, la conectividad, la promoción, las infraestructuras y la conectividad, así como un último eje para la construcción de paz a través del turismo (Fajardo, 2017, s.p).

De esta manera las medidas pasan, primeramente, por dotar de una mayor gestión turística a los departamentos, incorporando el turismo a las mesas sectoriales de las Comisiones Regionales de Competitividad (Plan Nacional de Desarrollo, 2014: 30). Así, la competitividad pretende reforzarse tanto en los destinos como en las empresas del sector, a partir del aprovechamiento de los atractivos, el fortalecimiento, formalización y capacitación de las comunidades y la certificación e innovación en productos y servicios (Plan Sectorial de Turismo, 2014: 37). También se contará con el Plan Estratégico de Seguridad Turística, llevado a cabo por la Policía de Turismo y el Consejo Superior de Seguridad Turística, y que buscará su consolidación en los territorios turísticos.

Otro eje estratégico será la conectividad aérea, marítima, fluvial, terrestre y digital para los departamentos más turísticos - Bogotá, Bolívar, Antioquia, Valle del Cauca, San Andrés y Providencia, Atlántico, Norte de Santander, Santander, Magdalena, Risaralda, Nariño y Quindío (Plan Nacional de Desarrollo, 2014: 32). Más concretamente, se busca mejorar las carreteras para el transporte turístico, mejorar la calidad de las infraestructuras aeroportuarias, y respecto al transportes marítimo y fluvial, incrementar el número de cruceros, barcos y pequeñas embarcaciones, recuperando para el turismo náutico, la navegación fluvial por el río Magdalena (Plan Sectorial de Turismo, 2014: 37). En lo referente a la promoción turística, se pretende unificar las campañas de turismo doméstico e internacional, buscando incrementar el gasto y estancia tanto del turista doméstico como internacional (Plan Nacional de Desarrollo, 2014: 34; Plan Sectorial de Turismo, 2014: 44).

Dentro de estas políticas, se contemplan acciones y medidas especiales para los destinos que hayan sido afectados por el conflicto colombiano, en la medida en que contribuyan a un desarrollo más equilibrado entre las diferentes regiones (Fajardo, 2017, s.p). Bajo esta directriz, se crearon las llamadas "Regiones Piloto de Turismo y Paz", como productos turísticos de naturaleza que permiten vincular la relación entre turismo y paz, por medio de la mejora de la convivencia entre comunidades residentes a través de emprendimientos turísticos sostenibles (Plan Sectorial de Turismo, 2018: 37). En la actualidad, se han articulado hasta 8 regiones piloto, que integran más de 42 municipios: "Camino a Teyuna (Ciudad Perdida) de la Sierra Nevada de Santa Marta (Magdalena); "La Serranía de la Macarena" (Meta); "Mocoa y Valle de Sibundoy" (Putumayo); "Urabá - El Darién” (Antioquía - Chocó); Montes de María (Bolívar); Vichada (Vichada) y los departamentos de Cauca, Caquetá. Para estos territorios, el marco legal turístico contempla la creación 
de programa de promoción y mercadeo y ruedas de negocios, incluyendo asistencias técnicas y asesoría para su comercialización.

Finalmente, el programa “Turismo, Paz y Convivencia” compone el último eje estratégico del turismo en el marco del posconflicto a corto plazo, y tiene por objetivo integrar a otras regiones que han sido víctimas del conflicto armado en el mercado turístico nacional (Moscarella, 2014: 22). Estos territorios se componen, además de los destinos piloto anteriormente mencionados, de otras dos tipologías; los llamados "destinos emergentes", integrados por un total de 34 municipios, y los "destinos de posconflicto", integrados por más de 40 municipios. De esta manera, el programa, integra en la actualidad más de 100 municipios repartidos en 24 departamentos del país. Para optar al programa, se deben cumplir, al menos, dos criterios de selección; el primero de ellos, ser o haber sido afectados por el conflicto armado, y estar desarrollando una transición como territorios de paz a través de un proceso de reconciliación con las comunidades integrantes, $\mathrm{y}$, en segundo lugar, poseer vocación turística, entendida como la existencia de atractivos turísticos - de cualquier tipología o nivel de desarrollo-, y una voluntad manifiesta de que las actividad turística fomenten un clima de paz y convivencia entre turistas y habitantes, así como, finalmente, la existencia de condiciones que posibiliten la seguridad de los viajeros (MINCIT, 2016). Para el desarrollo e implementación de este programa, se pretende contar con el apoyo de diferentes actores implicados; la comunidad del territorio, el gobierno nacional, los departamentos, municipios y otros órganos públicos, así como otros actores, donde se incluyen los prestadores de servicios turísticos, otras empresas vinculadas al turismo y la academia.

Aunque este programa se está comenzando a aplicar por parte de las autoridades de turismo, refuerza las nuevas directrices de Colombia, apuntando a la necesaria relación entre turismo, paz y desarrollo. Si bien los retos son evidentes, la perspectiva es positiva respecto a la actividad turística en el posconflicto, tanto en una como otra dirección, y se entiende como un nuevo periodo de aperturismo turístico del país.

\section{Conclusiones: paz y turismo para Colombia}

El establecimiento del alto el fuego en el país y la firma del Acuerdo de Paz es un hecho demasiado reciente para establecer unas conclusiones sobre la repercusión que ambos han tenido en el turismo del país. No obstante, tras la firma del Acuerdo de Paz, el país se abre paso a una nueva situación histórica, en la cual, el turismo se constituye como uno de los sectores económicos con mayor proyección. De hecho, su importancia ya quedó reflejada unos meses antes de la firma, cuando, el 24 de agosto de 2016, y ante el eminente fin de 
la violencia en el país, el Presidente de la República señalaba que Colombia dejaría de ser vista como un país peligroso y ello generaría "más inversión, más turismo y más empleo". Esta referencia explícita a la actividad turística se vincula con una serie de posibles efectos positivos, de índole mayoritariamente económica, pero, además, de otra parte, la misma declaración evidencia que el fin de la violencia podrá conllevar una desvinculación del componente de inseguridad respecto de la imagen turística nacional e internacional del país.

Esta perspectiva, pone de manifiesto cómo la paz es vista como un componente necesario para el turismo, pero, además, y tal como lo reflejan los diferentes programas de turismo en el país, el turismo se está planteando como un elemento de desarrollo social, cultural y ambiental, que más allá de lo económico, se encamine hacia la reducción de las desigualdades y diferencias que tanto el propio conflicto, como otros contextos, han podido dejar al país (Rozo y Garavito, 2014: 60). Tal y como señalaba el secretario general de la OMT, en Medellín, el turismo puede y debe tener un papel "muy importante en el escenario de posconflicto, especialmente, por el rol que éste puede constituir en la unión del país" (MINCIT, 2015: s.p). En este sentido, el país cuenta con el respaldo institucional nacional e internacional, y ya se están implementando las primeras experiencias piloto, en las cuáles se busca que el conflicto armado puede ser reemplazado por actividades turísticas sostenibles para las comunidades y los territorios.

Es necesario, todavía, profundizar en las necesidades y características de los espacios turísticos que el país tiene, tanto para los destinos más maduros, como en aquellos que son emergentes. Igualmente, ha de avanzarse en el fortalecimiento institucional del sector y en la cooperación de todos aquellos actores turísticos y no turísticos, públicos y privados, además de las comunidades residentes y los turistas nacionales e internacionales. Sin embargo, en todo caso, las perspectivas del turismo en el país invitan a pensar en una fructífera relación simbiótica entre turismo y paz durante los años en que tenga que desarrollarse esta nueva etapa de posconflicto en Colombia. 


\section{Referencias bibliográficas:}

Acerenza, M.A. (2006). Conceptualización, origen y evolución del turismo. México: Editorial Trillas.

Anson, C. (1999). Planning for peace: the role of tourism in the afternath of violence. Journal of Travel Research, 38, $57-61$.

Araña, J.E y León, C.J. (2008). The impact of terrorism in tourism demand. Annals of Tourism Research, 35, 299 - 315.

Askjellerud, S. (2003). The Tourist: A Messenger of Peace?'. Annals of Tourism Research, 30 (3), 741-44.

Bassols, N. (2016). Branding and Promoting a country amidst a long-term conflict: The Case of Colombia. Journal of Destination Marketing \& Management, 5, 314-324.

Beirman, D. (2002) Marketing of tourism destination during a prolonged crisis: Israel and the Middle East. Journal on Vacation Marketing, 8 (2), 167 176.

Brida, J.G., Risso, W.A., Zapata - Aguirre, S., Pereyra, J.S. y Such, M.J. (2009). Turismo y crecimiento económico: un análisis empírico de Colombia. Estudios y Perspectivas en Turismo, 18 (1), 21 - 35.

Brida, J.G., Monterubbianesi, P.D., Zapata - Aguirre, S. (2011). Impactos del turismo sobre el crecimiento económico y el desarrollo. El caso de los principales destinos turísticos de Colombia. Pasos: Revista de Turismo y Patrimonio Cultural, 9 (2), 291 - 303.

Burns, P.M, Novelli, M. (2008). Tourism and Mobilities. Local - Global Connections. Oxfordshire: CAB International.

Butler, R.; Baum, T. (1999). The Tourism Potential of the Peace Dividend. Journal of Travel Research, 38 (1), 24 - 29.

Caro, G.; Bula, A. (1998). 1968 - 1998: treinta años de historia del turismo colombiano. Bogotá: Corporación Nacional de Turismo de Colombia.

Causevic, S. y Lynch, P. A. (2011). Phoenix Tourism. Post-Conflict Tourism Role. Annals of Tourism Research, 38 (3), 780-800.

Causevic, S.; Lynch, P.A. (2013). Political (in)stability and its influence on tourism development. Tourism Management, 34, 145 - 157.

Cavlek, N. (2002). Tour Operators and Destination Safety. Annals of Tourism Research, 29 (2), $478-496$.

Croes, R. (2012) Una exploración del potencial del turismo en la lucha contra la pobreza en América Latina. Diálogos Revista Electrónica de Historia, octubre, $41-63$.

DANE (2017) Producto Interno Bruto, Q3. Bogotá: Departamento Administrativo Nacional de Estadística y Ministerio de Comercio, Industria y Turismo. 
D'Amore, L. (1988). Tourism-The World's Peace Industry. Journal of Travel Research, 27, 35-40.

DNP (2014). Plan Nacional de Desarrollo. Bogotá: Plan Nacional de Desarrollo.

Drabek, T. (2000). Disaster Evacuations: Tourist - business managers rarely act as customers expect. Cornell Hotel and Restaurant Administration Quarterly, 41 (4), $48-57$.

Fajardo, K. (2017). Conversatorio "Estrategia de Turismo y Paz del MinCIT". Bogotá: Universidad Externado de Colombia.

Fuchs, G.; Pizam, A. (2011) "The importance of safety and security for tourism destination". Youcheng Wang y Abraham Pizam (Eds.). Destination Marketing and Management. Theories and Applications (300 - 311). Oxfordshire: CAB International.

Galtung, J. (1969). Violence, Peace and Peace Research. Journal of Peace Research, 6 (3), $167-191$.

Gómez, J.A. (2002). Turismo, conflicto armado y paz en Colombia: Apostándole al futuro. Anuario Turismo y Sociedad, 1, 57 - 69.

Jaramillo, R. (2006). La hora del turismo. Bogotá: Grupo Editorial Norma.

Keyes, M. (2012) War Tourism: Shaping Memory and Perception in Post-War Vietman. Summer Research, s.p.

Leiper, N. (1979). The framework of tourism. Annals of Tourism Research, 6, $390-407$.

Lepp, A. y Gibson, H. (2003). Tourist roles, perceived risk and international tourism. Annals of Tourism Research, 30, 606-624.

Leslie, D. (1996). Northern Ireland, Tourism and Peace. Tourism Management, 17 (1), 51-55.

Litvin, S.W. (1998). Tourism: The World's Peace Industry? Journal of Travel Research, 37 (1), $63-66$.

Mansfeld, Y. (1996) "Wars, tourism and the 'Middle East' factor". Abraham Pizam y Yoel Mansfeld, (eds). Tourism, Crime and International Security Issues (265 - 278). New York: Wiley.

Mathieson, A., Wall, G. (1982). Tourism Economic, Physical and Social Impacts. Michigan: Ongman.

Mawby, R.I. (2000). Tourists' perceptions of security: the risk fear paradox. Tourism Economics, 6, 109-121.

MINCIT (2007). Política de Turismo Cultural. Bogotá: Ministerio de Comercio, Industria y Turismo.

MINCIT (2014) Plan Sectorial de Turismo "Turismo para la construcción de la paz” (2014 - 2018). Bogota: Ministerio de Comercio, Industria y Turismo.

MINCIT (2015) “Así fue la Asamblea General en Medellín” [en línea] http:// www.mincit.gov.co/publicaciones/34790/asi_fue_la_asamblea_general_ de_la_omt [consultado el 15 de diciembre de 2017 ] 
MINCIT (2016). Turismo, paz y convivencia. Bogotá: Ministerio de Comercio, Industria y Turismo.

Moscarella, J. (2014) Informe de gestión (2012 - 2014). Bogota: Ministerio de Comercio, Industria y Turismo.

Moufakkir, O., Kelly, I. (2010). Tourism Progress and Peace. Oxfordshire: CAB International.

Ojeda, D. (2013). War and Tourism: The Banal Geographies of Security in Colombia's Retaking, Geopolitics, 18 (4), 759 - 778.

OMT (1980). Declaración de Manila. Madrid: Organización Mundial del Turismo.

OMT (2009). Estatutos. Madrid: Organización Mundial del Turismo.

OMT (2009). Colombia, de vuelta en el mapa del turismo mundial. Madrid: Organización Mundial del Turismo.

OMT (2013). Turismo en las Américas - Edición 2013. Madrid: Organización Mundial del Turismo.

Pizam, A., Tarlow, P. and Bloom, J. (1997) Making tourists feel safe: whose responsibility is it? Journal of Travel Research, 36 (1), 23-28.

Pizam, A. (1999). Comprehensive approach to classifying acts of crime and violence at tourism destinations and analyzing their differential effects on tourism demand, Journal of Travel Research, 38, 5-12.

Pizam, A. (2002) Editorial: Tourism and terrorism. International Journal of Hospitality Management 21, 1-3.

Pizam, A. and Mansfeld, Y. (2006) "Towards a theory of tourism security". Yoel Mansfeld y Abraham Pizam (eds). Tourism, Security and Safety: From Theory to Practice (1 - 27) Burlington: Elsevier Butterworth-Heinemann. Pratt, S.; Liu, A. (2016) Does Tourism Really Lead to Peace? A Global View. International Journal of Tourism Research, 18 (1), 82 - 90.

Richter, L.K., Waugh, W.L. (1986). Terrorism and tourism as logical companions. Tourism Management, 7 (4), 230 - 238.

Richter, L. (1992). "Political Instability and Tourism in the Third World". David Harrison (Ed.) Tourism and the Less Developed Countries (3546). Oxfordshire: CAB International.

Ríos, J. (2017). Breve historia del conflicto armado en Colombia. Madrid: Los Libros de La Catarata.

Rozo, E.; Garavito, L. (2014). Tourism in Colombia: Growth versus Development. Eduardo Fayos - Solá (Ed.) Tourism as an Instrument for Development. Londres: Emerald Group.

Ryan, C. (1993). Crime, violence, terrorism and tourism: an accidental or intrinsic relationship? Tourism Management, 14 (3), 173 - 183.

Salazar, N. (2006). Building a "Cultura of Peace" through Tourism: Reflexive and analytical notes and queries. Universitas Humanística, 62, 319 - 340. 
Santana, G. (2001). Tourism in South America. Nueva York: Routledge.

Savignac, A.R. (1994). WTO News, 3 (1) s.p.

Schluter, R. (2008). Turismo: una versión integradora. Buenos Aires: CIET.

Sönmez, S.F. (1998). Tourism, terrorism and political instability. Annals of Tourism Research, 25, 416 - 456.

Sönmez, S.F., Apostolopoulos, Y. y Tarlow, P. (1999). Tourism in crisis: managing the effects of terrorism. Journal of Travel Research, 38, 13-18.

Steene, A. (1999). Risk management within tourism and travel. Turizam, 47 (1) $13-18$.

Tarlow, P.E. (2006) Crime and tourism. John Wilks, Donna Pendergast y Peter Leggat (Eds.) Tourism in Turbulent Times: Toward Safe Experiences for visitors $(94-105)$. Oxford: Elsevier.

Tomljenovic, R. (2010). Tourism and Intercultural Understanding or Contact Hypothesis Revisited. Omar Moufakkir y Ian Kelly (Eds). Tourism, Progress and Peace (17 - 34). Wallingford: CAB International.

Toro, G. (2003). La política pública de turismo en Colombia. Anuario Turismo y Sociedad, 2, $9-15$.

Valencia, J. (1992). Cronología básica para una historia del turismo colombiano. Bogotá: Corporación Nacional de Turismo.

Valencia, J. (2001). Compendio de estadísticas del Turismo en Colombia. Bogotá: Corporación Nacional de Turismo.

Van Broeck, A.M. (2002). Turismo doméstico en Colombia en un contexto de conflicto armado (1996 - 2001). Anuario Turismo y Sociedad, 1, 44 - 60.

Velasques, C.M.; Van Broeck, A.M.; Posada, L.M. (2014). El pasado polémico de los años ochenta como atractivo turístico en Medellín. Anuario Turismo y Sociedad. 15, $101-114$.

Wahab, S. (1996). Tourism development: Competitive strategies and implications, Progress in Tourism and Hospitality Research, 2 (3 -4), 351 $-364$.

Winsteiner, W.; Wohlmuther, C. (2013). Peace sensitive Tourism: How tourims can contribute to peace. International Handbook on Tourism and Peace $(31-61)$. Austria: OMT.

Zuñiga - Collazos, A. (2015). Análisis de la investigación y desarrollo turístico en Colombia. Revista espacios, 36 (18), 9 - 26. 